\title{
Breakfast cereal consumption in young children: associations with non-milk extrinsic sugars and caries experience: further analysis of data from the UK National Diet and Nutrition Survey of children aged $1.5-4.5$ years
}

\author{
Sigrid A Gibson * \\ Independent Nutrition Consultant, 11 Woodway, Merrow, Guildford, Surrey GUI 2TF, UK
}

Submitted 21 May 1999: Accepted 23 September 1999

\begin{abstract}
Objective: This study examined the relationship between breakfast cereal consumption and non-milk extrinsic sugars (NMES) intake and the possible implications of this for caries in preschool children.

Methods: Data from the 1995 UK National Diet and Nutrition Survey (NDNS) of children aged 1.5-4.5 years were reanalysed. Four-day weighed food records and dental examinations were available on 1450 children living in private households in Britain. Children were classified by tertiles (age-adjusted) according to the proportion of energy derived from breakfast cereals, and the amount of NME sugar from cereals. There were no significant differences in social class background between any of the groups.

Results: Children with diets high in breakfast cereals as a proportion of total energy (top third) had lower proportional intakes of NMES, compared with low consumers of cereals (lowest third). Consumption of sweetened cereals was positively associated with NMES intake. However, caries experience was unrelated to breakfast cereal consumption, whether presweetened or not.

Conclusions: Although presweetened cereals are relatively high in NMES, their cariogenic potential is probably minimal in the circumstances in which they are normally consumed.
\end{abstract}

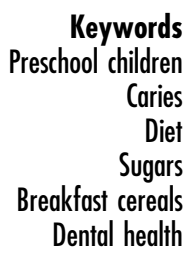

The prevalence of dental caries in young children in the UK fell dramatically between 1973 and 1983, due largely to the introduction and widespread use of fluoride toothpastes and other fluoride treatments. However, since 1983, progress has been slower, the proportion of 5 year olds with no decay experience rising slightly from $52 \%$ to $57 \%$ in $1993^{1}$. At the same time, there is evidence that the incidence of caries is increasing in certain groups, with the polarization related to social class inequalities ${ }^{2,3}$.

Frequent consumption of sugars and poor oral hygiene are commonly regarded as the most important behavioural factors in caries aetiology ${ }^{4}$. Dental health education materials and policy documents often place avoidance of sugary foods at the top of the list ${ }^{5}$, but many dental experts would agree that the most effective message for caries prevention is 'brush your teeth every day with a fluoride toothpaste ${ }^{6}$. Despite the broad consensus of opinion that sugars have a causal role in the aetiology of caries $^{7-9}$, the fact remains that epidemiological associations between dietary sugars and caries within western societies are weak ${ }^{10,11}$, while attempts at dietary intervention lack convincing proof of success ${ }^{12,13}$.
Presweetened cereals are particularly popular with children, and manufacturers are often criticized for targeting their marketing at this audience. Many dietary studies attest to the nutritional benefits of ready-to-eat cereals $^{14}$, but children's cereals are also perceived as excessively sugary and cariogenic. This can create a dilemma for health professionals and guilt for mothers who indulge their children's preferences. The present study has examined evidence for associations between breakfast cereal consumption, sugar intakes and caries experience in 1450 preschool children eating their normal diets. The data used were from a recent UK national survey that incorporated high-quality dietary assessments with dental examinations on each child ${ }^{15,16}$.

\section{Methods}

The UK NDNS of children aged $1.5-4.5$ years ${ }^{15,16}$ comprises the most recent nationally representative dietary survey of this age group for 25 years. The computerized data files for both the dietary and dental elements of the survey were requested from the Economic and Social Research Council Data Archive ${ }^{17}$ by the investigator (SG) and analysed using SPSS software ${ }^{18}$. The survey 
methodology is explained in full in the published reports and briefly outlined below.

The dietary data collected consisted of a 4-day weighed dietary record, completed by the child's main carer, together with a dietary interview to assess food frequency. In the data collection phase of the original study, the detailed recording procedure was carefully demonstrated to participants by a fieldworker who visited homes several times to check recording and to probe for missing items. Details of cooking and preparation methods, leftovers, spillages and foods eaten away from home were recorded. A Ministry of Agriculture, Fisheries and Food (MAFF) database, updated for the survey and comprising the nutritional composition of 6000 foods, was used to calculate nutrient intakes including NMES. Participants were only told about the dental component of the survey after completion of the dietary survey to reduce the likelihood of abnormal eating or selective underrecording. In a feasibility study prior to the survey, the dietary method was validated by the doubly-labelled water technique (to measure energy expenditure $)^{19}$. On average, the measures of intake and expenditure were extremely close, suggesting there was little underreporting. The 4-day dietary records (two weekdays, two weekend days) were reweighted to provide estimates of weekly consumption (five weekdays, two weekend days) ${ }^{15}$.

The dental examinations were carried out by 79 dentists from the National Health Service, all experienced in working with young children. Children with active decay (cavities extending into dentine or pulp), or with teeth filled or extracted due to decay, were all designated as positive for caries ${ }^{16}$. Dental examinations and interviews were completed for 1450 children, or $86 \%$ of the sample who completed dietary diaries.

\section{Analyses for the present study}

Average daily intakes, food intakes and their energy contribution (amounts per day) were used to calculate the percentage of energy each child obtained from breakfast cereals. NMES were expressed as a percentage of energy intake. Children within each year group (1.5-2.5, 2.5-3.5 and 3.5-4.5 years) were then classified, using tertile cut-offs, as low, medium or high consumers of breakfast cereals and of NMES. The age groups were then aggregated to provide intake groups comparable in their age/sex distribution. This ageadjustment was regarded as essential in view of the rising prevalence of caries with age. The amount of NMES each child obtained from breakfast cereals (as manufactured) was used to classify children by tertile of 'cereal sugars' in each age group. This allowed comparison between children with low, medium or high intakes of sweetened cereals in a manner that took account of the range of sugar concentration in these products.

\section{Results}

Breakfast cereal consumption and NMES intakes The association between proportional intakes of NMES and cereals was inverse; that is, children with the highest cereal intakes (as a percentage of energy) had the lowest concentration of NMES in the diet $(P=0.023)$, despite having diets higher in carbohydrate $(P<0.0001$; Table 1). There are two reasons for this inverse relationship: firstly, breakfast cereals were only a minor source of NMES for most children (providing, on average, 5\% of intake), and secondly, children who ate most cereal happened to eat less confectionery, biscuits, cakes and soft drinks. This more than compensated for their slightly higher intake of table sugar and jam (Table 2). These findings are consistent with other evidence that consumption of breakfast cereal is related to a range of health-conscious dietary behaviours ${ }^{14}$. There was no difference between cereal consumption groups in the proportion of children from manual backgrounds (53-55\% of children from manual backgrounds).

\section{Sweetened cereals and NMES}

Children in the top third of the distribution of sweetened cereals had diets highest in NMES (19.7\%; $P=0.001)$. However, the lowest NMES concentration (18.0\%) was found in the group with average consumption (Table 3).

\section{Sweetened cereals and caries experience}

Caries prevalence was unrelated to the consumption of cereals or cereal sugars (Tables 1 and 3). Figure 1 shows the rising prevalence of caries with age, and the contrasting lack of positive relationship with cereal sugars. In the oldest age group, the relationship actually appears to be inverse (chi-square linear association $P=0.019$ ). There was no difference in the proportion of children from manual backgrounds.

\section{Discussion}

The nutritional benefits of breakfast cereals are wellestablished but concerns are sometimes raised regarding their sugar content. In the young children surveyed, cereals made a relatively minor contribution to NMES intake ( $5 \%$ of total NMES intake). Even for the highest consumers of sweetened cereals the contribution was only $11 \%$ of total NMES. There was no convincing association to imply that sweetened cereal consumption increased the risk of caries. The paradoxical inverse trend noted in the oldest children (3.5-4.5 years) may warrant further examination and may reflect more health-conscious behaviours among high consumers.

While these results are inconclusive with regard to a cariogenic effect of sweetened breakfast cereals, there are a number of potential reasons why even pre- 
Table 1 Diet composition and caries prevalence by thirds of cereal consumption (\% energy)

\begin{tabular}{|c|c|c|c|c|c|}
\hline & \multicolumn{3}{|c|}{ Cereal consumption group } & \multirow[b]{2}{*}{$\begin{array}{c}\text { Total } \\
(n=1675)\end{array}$} & \multirow{2}{*}{$\begin{array}{c}\text { Difference } \\
\text { between } \\
\text { tertiles, } \\
P \text { value }\end{array}$} \\
\hline & $\begin{array}{c}1 \text { (low) } \\
(n=557)\end{array}$ & $\begin{array}{c}2 \text { (average) } \\
(n=561)\end{array}$ & $\begin{array}{l}3 \text { (high) } \\
(n=557)\end{array}$ & & \\
\hline \multicolumn{6}{|l|}{$\%$ energy from cereals } \\
\hline Mean & 1.6 & 5.4 & 10.6 & 5.9 & \\
\hline \multicolumn{6}{|l|}{ Total energy intake $\left(\mathrm{kJ}\right.$ day $\left.^{-1}\right)$} \\
\hline Mean & 4914 & 4881 & 4599 & 4798 & $<0.0001$ \\
\hline SE & 49 & 45 & 42 & 27 & \\
\hline \multicolumn{6}{|l|}{$\%$ energy from carbohydrate } \\
\hline Mean & 49.3 & 51.0 & 53.0 & 51.1 & $<0.0001$ \\
\hline SE & 0.3 & 0.2 & 0.2 & 0.2 & \\
\hline \multicolumn{6}{|l|}{$\%$ energy from NMES } \\
\hline Mean & 19.3 & 18.9 & 18.0 & 18.7 & 0.023 \\
\hline SE & 0.4 & 0.3 & 0.3 & 0.2 & \\
\hline \multicolumn{6}{|l|}{$\%$ energy from fat } \\
\hline Mean & 37.9 & 36.1 & 33.8 & 35.9 & $<0.0001$ \\
\hline SE & 0.2 & 0.2 & 0.2 & 0.1 & \\
\hline \multicolumn{6}{|l|}{$\%$ of children with caries } \\
\hline Mean & 18 & 16 & 16 & 17 & NS \\
\hline SE & 2 & 2 & 2 & 1 & \\
\hline \multicolumn{6}{|l|}{ Age (months) } \\
\hline Mean & 34.5 & 34.8 & 34.7 & 34.7 & NS \\
\hline SE & 0.4 & 0.4 & 0.4 & 0.2 & \\
\hline$\%$ from manual social class & 53 & 53 & 55 & 54 & NS \\
\hline
\end{tabular}

Table 2 Food intakes $\left(\mathrm{g} \mathrm{week}^{-1}\right.$ ) by thirds of cereal consumption (\% energy)

\begin{tabular}{|c|c|c|c|c|c|}
\hline & \multicolumn{3}{|c|}{ Cereal consumption level } & \multirow[b]{2}{*}{$\begin{array}{c}\text { Total } \\
(n=1675)\end{array}$} & \multirow{2}{*}{$\begin{array}{c}\text { Difference } \\
\text { between } \\
\text { tertiles, } \\
P \text { value }\end{array}$} \\
\hline & $\begin{array}{c}1 \text { (low) } \\
(n=557)\end{array}$ & $\begin{array}{c}2 \text { (average) } \\
(n=561)\end{array}$ & $\begin{array}{l}3 \text { (high) } \\
(n=557)\end{array}$ & & \\
\hline \multicolumn{6}{|c|}{$\%$ energy from cereals } \\
\hline Mean & 1.6 & 5.4 & 10.6 & 5.9 & \\
\hline \multicolumn{6}{|c|}{$\begin{array}{l}\text { Weekly intake }(g) \text { of: } \\
\text { Breakfast cereals }\end{array}$} \\
\hline Mean & 41 & 127 & 244 & 137 & $<0.0001$ \\
\hline SE & 2 & 2 & 5 & 3 & \\
\hline \multicolumn{6}{|c|}{ Biscuits and cakes } \\
\hline Mean & 187 & 183 & 161 & 177 & 0.004 \\
\hline SE & 6 & 6 & 6 & 3 & \\
\hline \multicolumn{6}{|l|}{ Bread } \\
\hline Mean & 299 & 279 & 267 & 282 & 0.009 \\
\hline SE & 8 & 7 & 7 & 4 & \\
\hline \multicolumn{6}{|c|}{ Confectionery } \\
\hline Mean & 160 & 148 & 117 & 142 & $<0.0001$ \\
\hline SE & 6 & 6 & 5 & 3 & \\
\hline \multicolumn{6}{|l|}{ Total fats } \\
\hline Mean & 48 & 40 & 37 & 42 & $<0.0001$ \\
\hline SE & 2 & 1 & 1 & 1 & \\
\hline \multicolumn{6}{|c|}{ Meat and meat products } \\
\hline Mean & 389 & 360 & 336 & 362 & 0.003 \\
\hline SE & 12 & 11 & 11 & 6 & \\
\hline \multicolumn{6}{|c|}{ Soft drinks* } \\
\hline Mean & 2851 & 2708 & 2326 & 2629 & $<0.0001$ \\
\hline SE & 98 & 82 & 82 & 51 & \\
\hline \multicolumn{6}{|c|}{ Sugar and jams } \\
\hline Mean & 30 & 30 & 35 & 31 & 0.037 \\
\hline SE & 2 & 2 & 2 & 1 & \\
\hline \multicolumn{6}{|c|}{ Savoury snacks } \\
\hline Mean & 78 & 66 & 54 & 66 & $<0.0001$ \\
\hline SE & 3 & 3 & 3 & 2 & \\
\hline
\end{tabular}

Differences in intake of milk, fruit, fruit juice and puddings were not statistically significant.

* Other than fruit juice. 
Table 3 Diet composition and caries prevalence by thirds of cereal sugars*

\begin{tabular}{|c|c|c|c|c|c|}
\hline & \multicolumn{3}{|c|}{$\begin{array}{l}\text { Cereal sugars group } \\
\text { (tertiles) }\end{array}$} & \multirow[b]{2}{*}{$\begin{array}{c}\text { Total } \\
(n=1675)\end{array}$} & \multirow{2}{*}{$\begin{array}{c}\text { Difference } \\
\text { between } \\
\text { tertiles, } \\
P \text { value }\end{array}$} \\
\hline & $\begin{array}{c}1 \text { (low) } \\
(n=558)\end{array}$ & $\begin{array}{c}2 \text { (average) } \\
(n=559)\end{array}$ & $\begin{array}{l}3 \text { (high) } \\
(n=558)\end{array}$ & & \\
\hline \multicolumn{6}{|l|}{ Total energy intake $\left(\mathrm{kJ}\right.$ day $\left.^{-1}\right)$} \\
\hline Mean & 4753 & 4804 & 4838 & 4798 & \multirow[t]{2}{*}{ NS } \\
\hline SE & 49 & 45 & 44 & 27 & \\
\hline \multicolumn{6}{|l|}{$\%$ energy from carbohydrate } \\
\hline Mean & 49.6 & 51.3 & 52.4 & 51.1 & \multirow[t]{2}{*}{$<0.0001$} \\
\hline SE & 0.3 & 0.2 & 0.2 & 0.2 & \\
\hline \multicolumn{6}{|l|}{$\%$ energy from NMES } \\
\hline Mean & 18.5 & 18.0 & 19.7 & 18.7 & \multirow[t]{2}{*}{0.001} \\
\hline S.E & 0.4 & 0.3 & 0.3 & 0.2 & \\
\hline \multicolumn{6}{|l|}{$\%$ energy from fat } \\
\hline Mean & 37.3 & 35.6 & 34.8 & 35.9 & \multirow[t]{2}{*}{$<0.0001$} \\
\hline SE & 0.2 & 0.2 & 0.2 & 0.1 & \\
\hline \multicolumn{6}{|l|}{$\%$ of children with caries } \\
\hline Mean & 18 & 18 & 14 & 17 & \multirow[t]{2}{*}{ NS } \\
\hline SE & 2 & 2 & 2 & 1 & \\
\hline \multicolumn{6}{|l|}{ Age (months) } \\
\hline Mean & 34.4 & 34.8 & 34.7 & 34.7 & \multirow[t]{2}{*}{ NS } \\
\hline SE & 0.4 & 0.4 & 0.4 & 0.2 & \\
\hline$\%$ from manual social class & 53 & 53 & 55 & 54 & NS \\
\hline
\end{tabular}

sweetened cereals may not be particularly cariogenic in practice. Firstly, the sucrose content of breakfast cereals may not adequately predict cariogenic potential ${ }^{20,21}$ because of the importance of other meal constituents. The in vitro study by Minton and Berry found a significant correlation between cereal sugar content

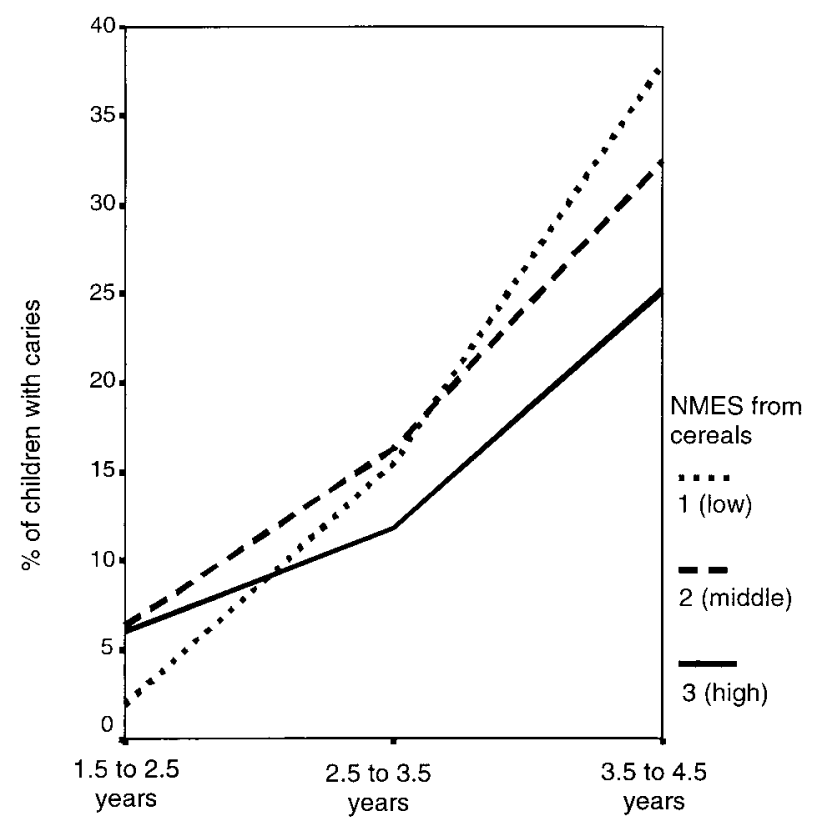

Age group of child at time of interview

Fig. 1 Caries prevalence by age group and intake of NMES from cereals. No significant association between caries and NMES from cereals was found and acid production, and longer oral retention times for presweetened cereals compared with low-sugar cereals; but this was only evident when the cereals were consumed without milk ${ }^{21}$. In contrast to some animal studies in which cereals are consumed dry ${ }^{22}$, most children eat cereals with milk. Another factor modifying the cariogenic impact of cereals is the frequency and timing of consumption. It is well-established that consuming sugary foods between meals is more likely to encourage caries than sugars at meal times ${ }^{23,24}$. The majority of young children in Britain consume breakfast cereals once a day as part of a morning meal ${ }^{25}$. More research is warranted regarding the cariogenic impact of different combinations and sequences of ingested food but these are difficult to study and therefore rarely considered $^{26}$.

With regard to dietary cofactors, the buffering (or acid neutralizing) action of other food constituents may influence the capacity for demineralization of enamel. An early animal study by Katz found the cariogenic potential of several breakfast cereals to be related, not to their sugar content, but to their buffering ability ${ }^{27}$. Most breakfast cereals consumed by children are eaten with milk, which has low cariogenic potential ${ }^{8}$ and is advocated as 'safe for teeth', Milk not only acts as a buffer to $\mathrm{pH}$ lowering, but the calcium present encourages remineralization of enamel ${ }^{24,28}$. Cocoa has also been shown to contain protective factors ${ }^{29,30}$. While some have expressed the opinion that these constituents are unlikely to override the detrimental effect of a high sugar content ${ }^{31}$, Minton and Berry's study suggests that the effect of cocoa is far from negligible ${ }^{21}$. Cocoa puffs 
(40\% sucrose) were found to exhibit a minimal $\mathrm{pH}$ change, with lower titratable acidity than some cereals of lower sucrose content ${ }^{21}$. Other food constituents that have anticaries potential include phytate, which adsorbs to the enamel surface preventing acid dissolution ${ }^{32}$. However, phytate levels are low in ready-to-eat cereals and the addition of phytate to cereals is undesirable because of its inhibitory effect on trace elements absorption, particularly of iron and zinc.

A further series of important factors affecting cariogenicity relate to oral retention times and toothbrushing. Cooked starch/sugar mixtures may adhere to the teeth and provide an opportunity for plaque growth after meals. However, toothbrushing after breakfast could reduce the cariogenic potential of breakfast cereals significantly, and around half of the children in this survey brushed their teeth twice a day, presumably morning and evening. A recent analysis of this survey's database suggests that toothbrushing frequency was a more powerful predictor of caries experience than consumption of dietary sugars or sugary foods, while the (weak) association between sugary foods and caries was only present in children who brushed less than twice a day ${ }^{33}$. Over $95 \%$ of all children were reported to use fluoride toothpaste ${ }^{16}$, so the benefits attributed to brushing are probably due to fluoride rather than mechanical cleansing per se.

Intervention studies have so far failed to show that caries can be reduced by modifying breakfast cereal consumption over $2-3$ years ${ }^{34-36}$. In the first study, 949 children aged 7-11 years were provided with free cereals (eight regular, six presweetened) for 2 years. There was no association between caries incidence and level of cereal consumption, presweetened or all types. The authors point to the importance of food consistency and the timing and conditions under which cereals are eaten ${ }^{34}$. The study by Rowe et al. of 370 adolescent boys, published in the same year, also failed to find a difference in caries experience between those who consumed cereals $(60 \%$ of which were presweetened) and those who consumed other foods at breakfast. They concluded that other factors, notably water fluoridation at $1.1 \mathrm{ppm}$ and 'oral health enlightenment' dominated dental caries causal relationships in the study ${ }^{35}$. The study by Wilson was designed to assess the impact of phosphate addition to cereals but neither this nor the type of cereal consumed appeared to have any impact on caries in adolescent boys ${ }^{36}$.

The inconclusive nature of the present study is less surprising when viewed in the light of the nonsignificant relationship found between caries and NMES in this survey ${ }^{33}$ and the weak relationships found between caries and sugar consumption in many other epidemiological studies ${ }^{11}$. Difficulties in measuring diet accurately may be partly responsible for this, although correlations between sugars and caries remain poor even in prospective studies using reliable dietary assessment methods. In the study by Rugg-Gunn, for example, sugar intake accounted for a mere $2 \%$ of the variance in caries $^{37}$. It has been suggested that the absence of a significant correlation between sugar intakes and caries in western societies may be because the caries/sugar relationship is described by a sigmoid curve, with western societies on the upper flattened area ${ }^{10,31}$. This would imply that a significant reduction in sugar intakes would be required to achieve a relatively small improvement in caries rate. Whilst it is claimed that 'if there is no sugar in the diet, caries can be virtually eliminated ${ }^{37}$ this ideal is impractical. Indeed, in a recent systematic critical review of more than 200 studies concerned with oral health promotion, only two out of four studies attempting to change dietary habits were successful, while none showed a reduction in caries consequent to a sugar reduction programme ${ }^{12,13}$.

Taken together with other evidence, therefore, the results of this study caution against generalizations relating to the cariogenicity of foods based on their sugar content. In practice, it appears that children who eat above-average quantities of presweetened cereals tend to have diets marginally higher in NMES than other children, but have a similar risk of caries. Further work may be justified to examine the diet/caries association among children with an infrequent toothbrushing habit. Meanwhile, there would appear to be little basis on which to discourage consumption of sweetened breakfast cereals by young children, given their considerable nutritional benefits.

\section{Acknowledgements}

This work was supported by a grant from the Kellogg Company (UK) Limited.

\section{References}

1 O'Brien M. Children's Dental Health in the United Kingdom 1993. London: HMSO, 1994.

2 Downer MC. The 1993 national survey of children's dental health. Br. Dent. J. 1995; 178: 407-12.

3 Davies RM, Hawley GM. Reasons for health inequalities in the dental health of children. J. Inst. Health Educ. 1995; 33: 88-9.

4 Department of Health. An Oral Health Strategy for England. London: Department of Health, 1994.

5 Levine R, ed. The Scientific Basis of Dental Health Education: a Policy Document. London: Health Education Authority, 1996.

6 Kay EJ. Evidence-based dental health promotion. Good Diet. Pract. News 1997; 8(2): 1-3.

7 Rugg-Gunn AJ. Diet and dental caries. In: Murray JJ, ed. The Prevalence of Dental Disease, 2nd edn. Oxford: Oxford University Press, 1973; 4-96.

8 Department of Health and Social Security. Dietary Sugars and Human Disease. Committee on Medical Aspects of Food Policy, Report on Health and Social Subjects No. 37. London: HMSO, 1989. 
9 Department of Health. Dietary Reference Values for Food Energy and Nutrients for the United Kingdom. Report on Health and Social Subjects No. 41. London: HMSO, 1991.

10 Woodward M, Walker AR. Sugar consumption and dental caries: evidence from 90 countries. Br. Dent.J. 1994; 176(8): 297-302.

11 Walker AR. Nutritional and dental implications of high and low intakes of sugar. Int. J. Food Sci. Nutr. 1995; 46(2): $161-9$.

12 Kay EJ, Locker D. Is dental health education effective? A systematic review of the current evidence. Community Dent. Oral Epidemiol. 1996; 24: 231-5.

13 Kay EJ. Caries prevention - based on evidence? Or an act of faith? Br. Dent. J. 1998; 185: 432-3.

14 Ruxton CHS, Kirk TR. Breakfast: a review of associations with measures of dietary intake, physiology and biochemistry. Br. J. Nutr. 1997; 78(2): 199-213.

15 Gregory JR, Collins DL, Davies PSW, Hughes J, Clarke P. National Diet and Nutrition Survey: Children aged 1.5 to 4.5 years. Vol. 1. Report of the Diet and Nutrition Survey. London: HMSO, 1995.

16 Hinds K, Gregory JR. National Diet and Nutrition Survey: Children aged 1.5 to 4.5 years. Vol. 2. Report of the Dental Survey. London: HMSO, 1995.

17 Economic and Social Research Council (ESRC) Data Archive, University of Essex, Colchester CO4 3SQ, UK.

18 SPSS UK Ltd, St Andrews House, West Street, Woking, Surrey GU21 1EB, UK.

19 Davies PSW, Coward WA, Gregory J, White A, Mills A. Total energy expenditure and energy intake in the pre-school child: a comparison. Br. J. Nutr. 1994; 72: 13-20.

20 Edgar WM. Prediction of the cariogenicity of various foods. Int. Dent. J. 1985; 35: 190-4.

21 Minton KL, Berry CW. Cariogenic potential of presweetened breakfast cereals. Pediatr. Dent. 1985; 7: 282-6.

22 McDonald JL Jr, Stookey GK. Animal studies concerning the cariogenicity of dry breakfast cereals. J. Dent. Res. 1977; 56(8): 1001-6.

23 Rugg-Gunn AJ, Hackett AF, Appleton DR, Jenkins GN, Eastoe JE. Relationship between dietary habits and caries increment assessed over two years in 405 English adolescent school children. Arch. Oral Biol. 1984; 29(12): 983-92.
24 Ismail AI. Food cariogenicity in Americans aged from 9 to 29 years assessed in a national cross-sectional survey, 1971-74. J. Dent. Res. 1986; 65(2): 1435-40.

25 Kelloggs Company of Great Britain Ltd. The Breakfast Report 1997. Kelloggs Company Ltd, Manchester.

26 Geddes DA. Diet patterns and caries. Adv. Dent. Res. 1994; 8(2): 221-4.

27 Katz S, Olson BL, Park KC. Factors related to the cariogenic potential of breakfast cereals. Pharmacol. Ther. Dent. 1975 ; 2(2): 109-31.

28 Bibby BG, Huang Ct, Zero D, Mundorff SA, Little MF Protective effect of milk against in vitro caries. J. Dent. Res. 1980; 59: 1565-70.

29 Palenik C, Park K, Katz S, Stookey G. Effect of water soluble components derived from cocoa on plaque formation. $J$. Dent. Res. 1979; 58: 1749.

30 's-Gravenmade EJ, Jenkins GN. Isolation, purification and some properties of a potential cariostatic factor in cocoa that lowers enamel solubility. Caries Res. 1986; 20(5): 433-6.

31 Moynihan PJ. The relationship between diet, nutrition and dental health: an overview and update for the 90's. Nutr. Res. Rev. 1995; 8: 193-224.

32 Magrill DS. The reduction of the solubility of hydroxyapatite in acid by the adsorption of phytate from solution. Arch Oral Biol. 1973; 18: 591-600.

33 Gibson S, Williams S. Dental caries in pre-school children associations with social class, toothbrushing habit and consumption of sugars and sugar-containing foods. Further analysis of data from the National Diet and Nutrition Survey of children aged $1.5-4.5$ years. Caries Res. 1999; 33(2): 10113

34 Glass RL, Fleisch S. Diet and dental caries: dental caries incidence and the consumption of ready-to-eat cereals J. Am. Diet. Assoc. 1974; 88: 807-13.

35 Rowe NH, Anderson RH, Wanninger LA. Effects of ready-toeat breakfast cereals on dental caries experience in adolescent children: a three-year study. J. Dent. Res. 1974; 53: 33-6.

36 Wilson CJ. Ready-to-eat cereals and dental caries in children a three-year study. J. Dent. Res. 1979; 58(9): 1853-8.

37 Rugg-Gunn AJ. Diet and dental caries. Dent. Update 1990; 17(5): 198-201. 